\title{
Research on black-dot defects on galvanized thick sheet surface after galvanizing line
}

\section{ZHANG Jianqiang ${ }^{1,2}$ WANG Yongwei ${ }^{2}$ CHEN Changfeng ${ }^{1}$, ZHENG Yanjun ${ }^{1 *}$, LI Yan ${ }^{2}$, ZHANG Xi ${ }^{2}$,YANG Jianwei ${ }^{2}$, ZHANG Jianhua ${ }^{3}$, Filippo Placidi ${ }^{2}$, ZHANG Nan ${ }^{2}$}

(1 College of Science, China University of Petroleum (Beijing), Beijing, 102249;

2 Shougang Research Institute of Technology, Beijing, 100043;

3 Beijing Automotive Technoloty Center, Beijing, 101300;

4 College of metallurgical engineering University of Science and Technology, Beijing, 100083)

Key Words: Construction Materials, local oxidation, SEM, terms of settlement

\begin{abstract}
The black-dot defects on galvanized thick sheet surface after galvanizing line, which is the traditional construction materials with $1.5 \mathrm{~mm}$ thickness, was studied. Characterizations of the research samples were carried out using a SEM in order to understand the causes of the defects. The results showed that the local oxidation mainly leaded to the surface defects. What's more, the bad conditions of touched rollers also results in the black-dot. The paper also discussed the terms of settlement.
\end{abstract}

\section{Introduction}

In the process of production of thick hot galvanized sheet, roughly speaking, $1.5 \mathrm{~mm}$ above, the steel surface defects often appear with the appearance of black horizontal stripes, always called black-dot. Specificly, embodied on the strip surface along the width direction, and the distribution in the length was about $1 \mathrm{~cm}$. When the defects were serious, the touch is obvious with hands. As shown in Figure $1^{[1-2]}$.

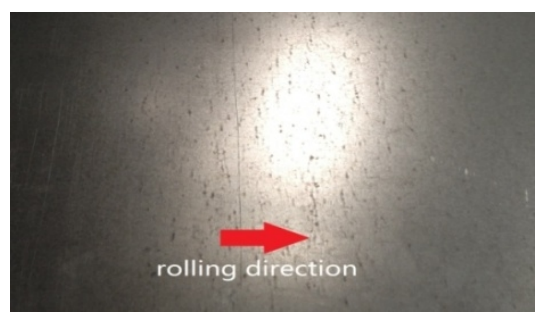

Figure1 Black-dot defects on galvanized thick sheet surface

\section{Experimental}

\section{Material used for study.}

The material used for this work is thick steel sheet. The composition of the material supplied is shown in table 1. 
Table 1 Chemical composition of the steel (wt. \%) that used for studies

\begin{tabular}{ccccccc}
\hline Element & $\mathrm{Fe}$ & $\mathrm{P}$ & $\mathrm{Si}$ & $\mathrm{C}$ & $\mathrm{Mn}$ & $\mathrm{Nb}$ \\
\hline Wt. \% & Bal & 0.01 & 0.01 & -- & 0.22 & -- \\
\hline
\end{tabular}

\section{Experimental methods.}

The experiments utilized the thick specification products of Shougang Jing tang Mill. The SEM was employed to analysis the surface microstructure and components of defects' location. The surface after cleaning up by dilute hydrochloric acid corrosion inhibitor was researched as well. Ultimately, according to the field experience, the terms of settlement were discussed ${ }^{[3]}$.

\section{Results and Discussion}

\section{Cause analysis -SEM analysis}

Defect location with surface topography had obvious difference with normal position. The organization of normal position was a combination of white plain area and black pit area; among of them the black area was the surface pits left on the zinc layer by working roller of skin pass mill, while the white area was the flat area for finishing after galvanized. Defect position the zinc layer on the surface, even also flat, presented some black hemp dots, as shown in Figure 2. The zinc layer surface present a slightly uneven feeling.

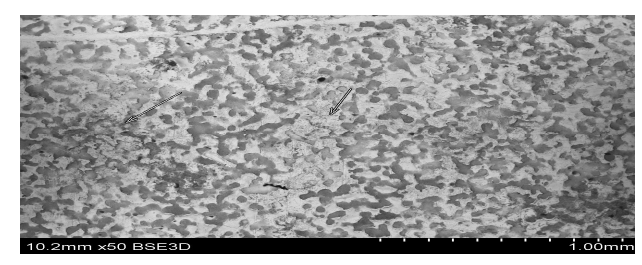

Figure 2 The morphology of black dot defects under SEM

Under the SEM, the zinc layer composition of different locations on the surface was analyzed, as shown in Figure 3 and Table 2. Location 2 oxygen content was as high as $26 \%$, significantly higher than normal galvanized flat position after finishing passivation. This indicated that black horizontal stripes existed oxidation phenomenon in the zinc layer surface.

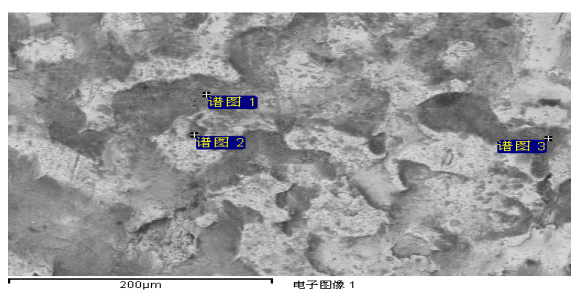

Figure 3Composition of SEM analysis 
Table 2 Chemical composition of the steel (wt. \%) that used for studys

\begin{tabular}{llllllllll}
\hline Locations & $\mathbf{O}$ & Al & $\mathbf{P}$ & $\mathbf{S}$ & $\mathbf{C l}$ & $\mathbf{K}$ & $\mathbf{C r}$ & $\mathbf{M n}$ & $\mathbf{Z n}$ \\
\hline Location 1 & 18.45 & & 3.05 & & & & 2.77 & & 75.73 \\
\hline Location 2 & 26.23 & & 2.22 & 0.72 & 11.60 & 3.00 & 4.55 & 1.58 & 50.11 \\
\hline Location 3 & 28.88 & 1.12 & 3.70 & & 1.31 & 2.37 & 5.80 & 2.61 & 54.22 \\
\hline
\end{tabular}

Surface with defects were cleaned up with dilute hydrochloric acid corrosion inhibitor in order to get rid of the zinc layer surface. After removing zinc coating, appearances of plate on the surface were as shown in Figure 4 and Figure 5. It was obviously visible from the figure that by removing the zinc layer, on the substrate surface there were slight traces under the SEM, the defect position corresponding to the substrate surface presented some slight sags. The reasons were that defect location in zinc and crest of position, the zinc layer around the zinc layer had large thickness, when the steel were finishing, the pressure of the zinc layer was larger, resulting in slight dents on and in the substrate

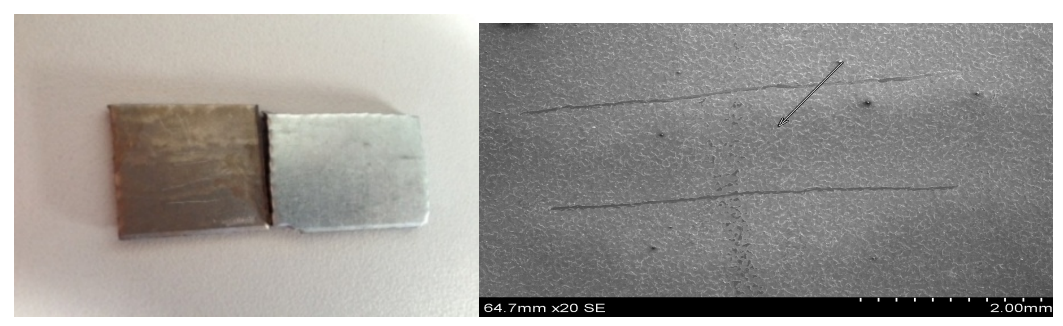

Figure 4 Macro-surface of substrate surface after cleaning Figure 5 Micro-surface of substrate surface after cleaning under SEM

\section{Discussion}

Therefore, the causes could be drafted that, during the thick specifications galvanized sheet production, due to the larger the steel plate internal heat of core, liquid zinc of the strip was still not completely solidified on the surface of the strip after air knives, and under the action of gravity along the strip steel and backflow of zinc liquids, leading to the formation of undulations. The air came from the air knife at high temperature caused the local partial oxidation, forming black horizontal stripes. Due to large strip thickness, cooling fan even at maximum power was not enough to lower the temperature of the steel strip, causing that the temperature of top roller was too high. What's more, the friction of the strip down side with the top roller caused more serious defects ${ }^{[4]}$.

\section{Conclusions}

\section{Terms of settlement}

1) Decrease the temperature of strip steel in zinc pot and liquid zinc

The temperature of strip into the zinc pot was so high $\left(460^{\circ} \mathrm{C}-465^{\circ} \mathrm{C}\right)$ that it was difficult to cooling as discussed above. Therefore reducing temperature from $460-465^{\circ} \mathrm{C}$ to $450-460^{\circ} \mathrm{C}$, could reduce the core hot of strip, making surface liquid zinc temperature low after the airway, decrease the 
undulations caused by liquid zinc zinc ups and downs, as shown in Figure 5.

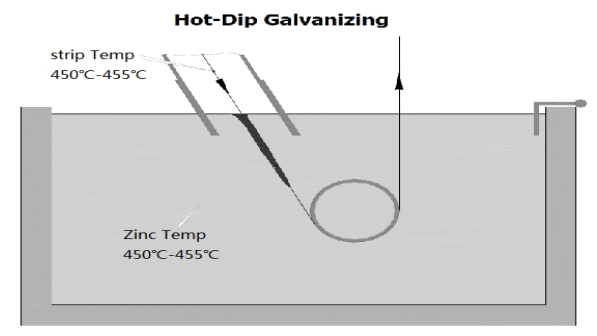

Figure 6 Decrease the temperature of strip steel in zinc pot and liquid zinc

2) Adjusting the parameters of the air knife and blowing nitrogen gas

Appropriate increasing the distance between the air knife and strip, increasing the height from air knife to zinc liquid surface, augmenting the injection pressure were the adopted. Through the above methods and air knife parameters adjustment, could increase the cooling capacity of air knife on strip, reduce zinc rolling defects occurrence. Compared with the air injection, instead of nitrogen injection could obviously improve the zinc layer on the surface and reduce the oxide black phenomenon

3) Opening a window for cooling tower

Before the reformation, the internal temperature of the cooling tower was so high, and the internal heat dissipating was hard, leading to the temperature of top roller reached more than 280 . As shown in figure 6 , a window was put for top roller.

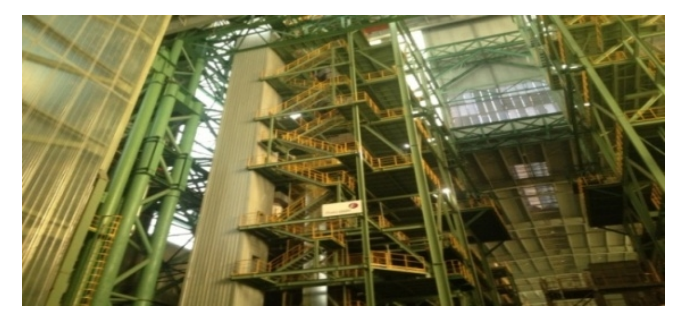

Figure 7 Opening a window for cooling tower

4) Replacement of the top roller

Due to long time under high temperature and the strip surface friction, the top roller' surface condition was bad, therefore, to deal with the top roller for regular replacement two times per yea. as shown in Figure 7.

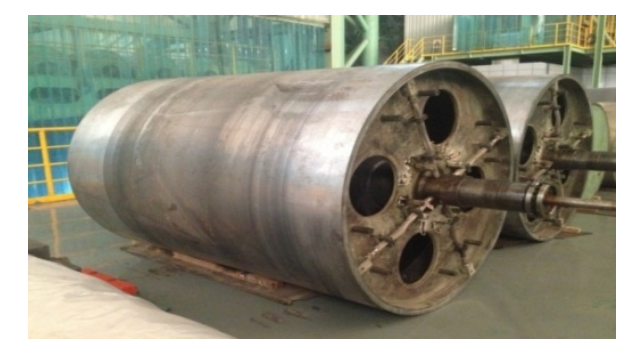

Figure 8 Replacement of the top roller

\section{The effect after the technical improvement}

Adopting the above measures, the production started again, black horizontal stripes obviously improve or even were eliminate. The comparison was taken between the samples with 
measures-before and measures-after respectively. Obviously, black dots (black horizontal stripes) from galvanized sheet surface have markedly improved, as shown in Figure 8.

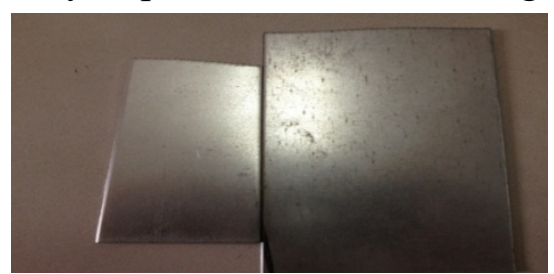

Figure 9 the effect after the technical improvement

\section{References}

[1] J.Lis, B.Gajda, A.K. Lis. Proceedings 12th International Scientific Conference "Achievements In Mechanical \&Matreials Engineering, Gliwice-Zakopane, AMME’2003,(2003) 605-608.

[2] A.K. Lis, B.Gajda. 11th International Scientific Conference on Contemporary Achievements in Mechanics, Manufacturing and Materials Science, Zakopane (2005) 585-591.

[3] E. Girault, A. Martens, P. Jacques, Y. Houbaert, B. Verlinden,J. van Humbeeck. Scripta Materialia 44 (2001) 885-892.

[4 O.A. Girina, N.M. Fonstein: Developments in Sheet Products for Automotive Applications. Materials Science \&Technology (2005) 65-76. 